\title{
Study on efficiency of locking compression plate for fracture of upper end of tibia
}

\author{
Rao D.R. ${ }^{1}$, Kanth K.R. ${ }^{2}$ \\ ${ }^{1}$ Dr. D. Rama Rao, Associate Professor, Department of Orthopaedics, GSL Medical College and General Hospital, \\ Rajahmundry, ${ }^{2}$ Dr. K. Ravi Kanth, Assistant Professor, Department of Orthopaedics, GSL Medical College and General \\ Hospital, Rajahmundry, Andhra Pradesh, India.
}

Corresponding Author: Dr. K. Ravi Kanth, Assistant Professor, Department of Orthopaedics, GSL Medical College \& General Hospital, Rajahmundry, Andhra Pradesh, India. E-mail: drravikondreddi@gmail.com

\begin{abstract}
Background: Fractures of proximal end tibia have historically been difficult to treat because of its subcutaneous location of the anteromedial surface of the tibia. Locking compression plate device offers potential biomechanical advantage over other methods. Locking compression plate has added advantage of the ability to manipulate and reduce the small and often osteoporotic fracture fragments directly. The present study objective was to compare the efficiency of locking compression plate in treatment of fractures with other standard methods of treatment. Method: In the present study, 20 patients with closed fracture of upper end of tibia were studied. All the cases were treated at GSL General Hospital, between 2015 \& 2017 and followed for a minimum of 6 months. The method used for fracture fixation was closed or open reduction and internal fixation with locking compression plate. The duration of follow up was 6 months. Result: In the present study the commonest mode of injury being the road traffic accident $90 \%$. There was Left sided predominance, compared to the right side. Most of the patients fall into type III, type IV, type V and type VI schatzker's classification. $14(70 \%)$ patients showed excellent result and $5(25 \%)$ patients showed good outcome. Conclusion: Locking Compression Plate is an important armamentarium in treatment of fractures around knee especially when fracture is severely comminuted and in situations of osteoporosis.
\end{abstract}

Keywords: Locking compression plate, Upper end of tibia, Modified Rasmussen criteria, Internal fixation.

\section{Introduction}

Ever since the advent of high velocity transport system, there is an alarming increase in RTA with increased orthopaedic related morbidity and mortality. Proximal tibia being involved in body weight transmission through knee joint and leg, it plays a vital role in knee function and stability [1]. Fractures of proximal end tibia have historically been difficult to treat because of its subcutaneous location of the anteromedial surface of the tibia. Severe bone and soft tissue injuries is not infrequent and there is high incidence of open fracture compared with other long bones [2]. The aim of surgical treatment of proximal tibial fractures is to restore and preserve normal knee function, which can be accomplished by anatomical restoration of articular surfaces, maintaining mechanical axis, restoring ligamentous stability and preserving a functional pain free range of motion of knee[1].

Manuscript Received: $4^{\text {th }}$ July 2019

Reviewed: $12^{\text {th }}$ July 2019

Author Corrected: $18^{\text {th }}$ July 2019

Accepted for Publication: $22^{\text {nd }}$ July 2019
The incidence of malunion, non-union and infections are relatively high in many reported series, causing significant long term disability. Over the last decade plate fixation has become popular for the treatment of fractures of proximaltibial fractures.

Locking compression plates (LCP) are a hybrid of plate technology and percutaneousbridge plating using locked screws as a fixed angle device.

Locking compression plate device offers potential biomechanical advantage over other methods by,

- Better distribution of forces along the axis of bone

- Substantially reducing failure of fixation in osteoporotic bones

- Reducing the risk of a secondary loss of intraoperative reduction by locking withscrews to the plate

- Unicortical fixation option 


\section{Research Article}

- Better preservation of blood supply to the bone as a locked plating does not rely on plate bone compression.

- Provide stable fixation by creating a fixed angle construct and angularstability.

- Early mobilisation.

Locking compression plate has added advantage of the ability to manipulate and reducethe small and often osteoporotic fracture fragments directly [3-5].

The study with short term follow up that the tibialLISS system worked well at stabilizing difficult fractures of tibial plateau and proximal tibia with a low incidence of In another study, about $96.7 \%$ patients had acceptable outcome (70\% excellent and $26.7 \%$ good) [6] complications which are involved proximal tibial fracture managed using LCP [7].

Keeping above facts in our mind, the present study was undertaken to find out efficiency of locking compression plate in treatment of fractures

Objectives: To compare the efficiency of locking compression plate in treatment of fractures with other standard methods of treatment.

\section{Material and Methods}

In the presentprospective study design, 20 patients with closed fracture of upper end of tibia were studied. All the cases were treated at GSL General Hospital, between $1^{\text {st }}$ Nov $2015 \& 31^{\text {st }}$ Oct 2017 and followed for a minimum of 6 months. Informed consent was obtained from each patient. Institutional Ethical committee approval was obtained before beginning of the study.

The method used for fracture fixation was closed or open reduction and internal fixation with locking compression plate. The duration of follow up is 6 months.

Patient selection: Patients admitted to GSL General hospital Rajahmundry with fracture upper end of tibia

a) All types of fracture of upper end of tibia (SCHATZKER TYPE I to 6) were included in the study.

b) Only closed fractures were considered.

c) Pediatric patients and pathological fractures excluded.

\section{Inclusion criteria}

1. Those patients who are above the age of 20 yrs and managed surgically are included in the study

2. Patients presenting with proximal tibial fractures with or without osteoporotic changes are included in the study

\section{Exclusion criteria}

1. Patients with open proximal tibial fractures

2. Children with proximaltibial fractures in whom, growth plate is still open.

3. Patient with pathological proximal tibial fractures other than osteoporosis

4. Patients lost in follow - up

5. Patients managed conservatively for other medical reasons.

6. Proximal tibial fractures with neurovascular compromise.

Implant used: The plate and screws are manufactured from $316 \mathrm{~L}$ stainless alloy with gundrilling technique. The locking compression plates are available from 4 holed to 14 holed. With $4 \mathrm{~mm} / 4.5 \mathrm{~mm}$ thickness plate for upper end of tibia. Anatomically precontouredplate head with soft edges.Locking screws in the head of the plate for a secure support.The head of the locking screw is threaded which gets locked to the plate as it is tightened.LCP combi-holesin the plate shaftIntraoperative choice between angular stabilityand/or compression.

Preoperative planning and preparation:Fractures were classified with the help of radiographs and CT according to the shatzker classification. Preoperative calculation was done to ascertain the size of the plate, accurate size of locking, cortical and cancellous screws after subtraction of the magnification factor. 


\section{Research Article}

The limb to be operated was shaved and prepared a day before scheduled surgery. One gram of second third generation intravenous cephalosporin was injected previous night and early morning on the day of surgery.

Surgical procedure: Surgery is done with tourniquet. For fractures of the lateral condyle, an anterolateralincision is made, starting $3 \mathrm{~cm}$ above the patella proximally and extending distally below theinferior margin of the fracture site. This incision provides good exposure, while avoiding skincomplications.Fascial incision parallel to the anterior border of the iliotibial tract is done. The plane ofdissection over the anterior patella should be below the fascia, which supplies blood to theprepatellar skin. If necessary for exposure, a portion or all of the iliotibialband from itsinsertion on the Gerdy tubercle is made. To expose the longitudinal fracture of the lateral condyle, the origin of the extensor muscles is stripped from the anterolateral aspect of the condyle. The horizontal limb of the incision is extended laterally from the tibial tuberosity. Reflect the muscle origin laterally until the fracture line is exposed.

A periosteal elevator is inserted well beneath the depressed articular fragments, and by slow and meticulous pressure the articular fragments and compressed cancellous bone are elevated in one large mass. This produces a large cavity in the metaphysis that must be filled with bone. Unless this is done, re-displacement and settling can occur. It was preferredthat packing cancellous bone into the defect because this much more nearly conforms to the defect cavity. Bone can be obtained from either the iliac crest or the lateral femoral condyle. It was observed that cancellous grafts from the bone bank and hydroxyapatite bone graft substitute also are satisfactory.

As the fragments are elevated and reduced, temporarily fix them with multiple small Kirschner wires. Locking compression plate is used for fixation. This plate is applied to the anterolateral tibial condyle which is precontoured to conform to the condyle and proximal metaphysis. When properly contoured, it is secured to the condyle with appropriate locking/plain cancellous screws of sufficient length to engage the opposite medial cortex. Locking/Cortical screws (4.5$\mathrm{mm}$ ) are used to attach the plate to the shaft of the tibia which may be unicortical when locking screws are used.

After stable fixation, wound is closed in layers. LCP is used as LISS with minimal incision over the lateral aspect when closed reduction is done.

Post operative protocol- The First follow up was done at 6 weeks, during which an X-ray was taken to look for signs of fracture union and loss of reduction if any.

The second follow up was done at 12 weeks during which one more X-ray was done and a clinical evaluation of union done. Based on the clinical and radiological signs of union patients were allowed partial weight bearing and gradually progressed to full weight bearing.

The patients were then followed up at 24 weeks, during which time the anatomic and functional evaluation was done using the modified Rasmussen clinical and radiological criteria [8].

\section{Clinical pictures}

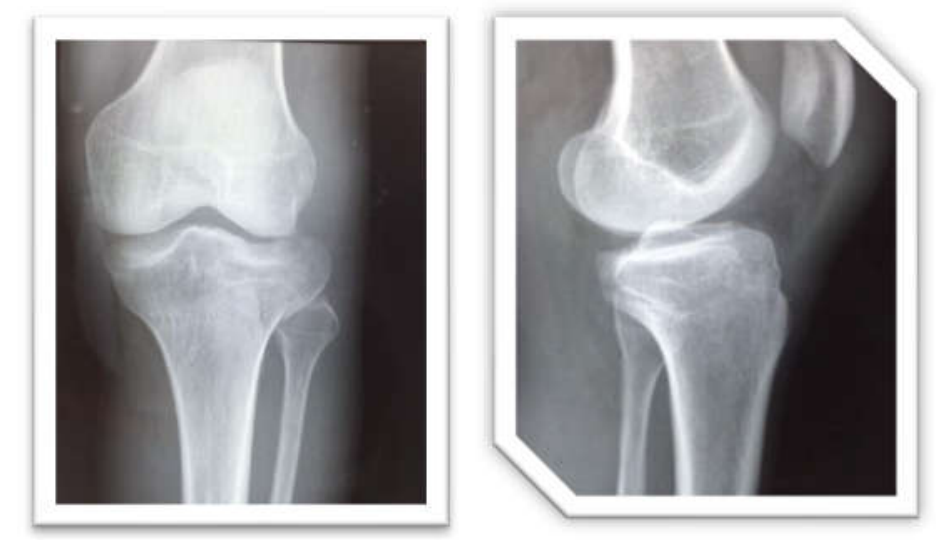

Figure-1:Pre-operative X-ray of patient 


\section{Research Article}

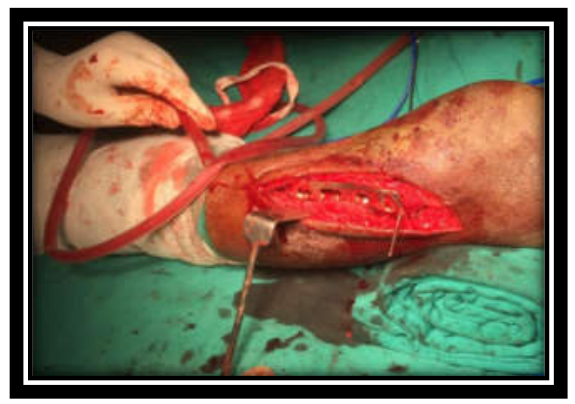

Figure-2: Intra-operative procedures picture
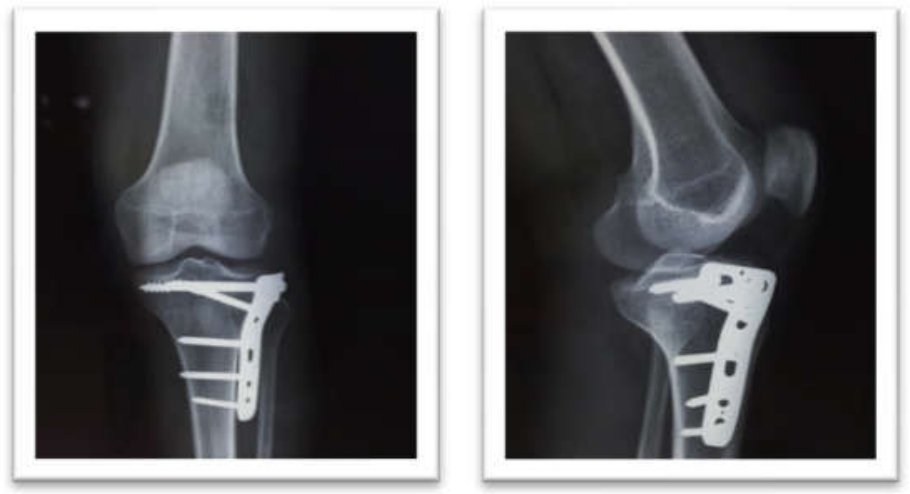

Figure-3:After operation, X-ray of patient
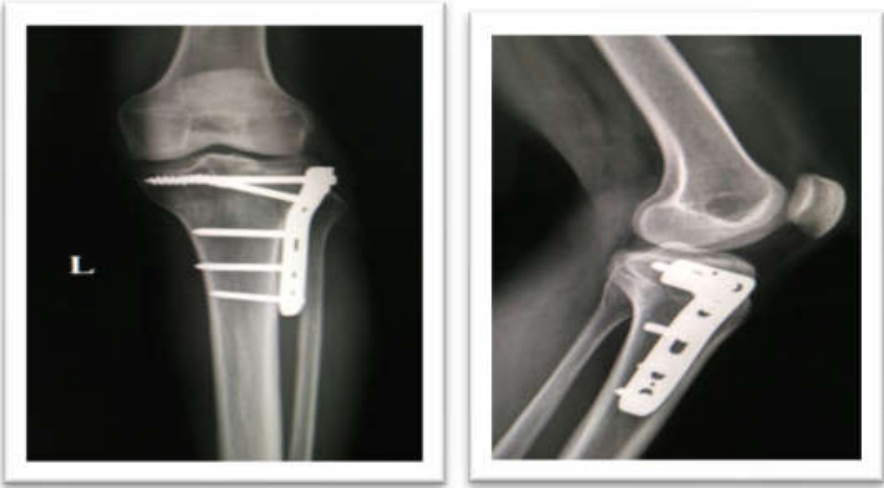

Figure-4:6 weeks post operative follow-up - X-ray of patient
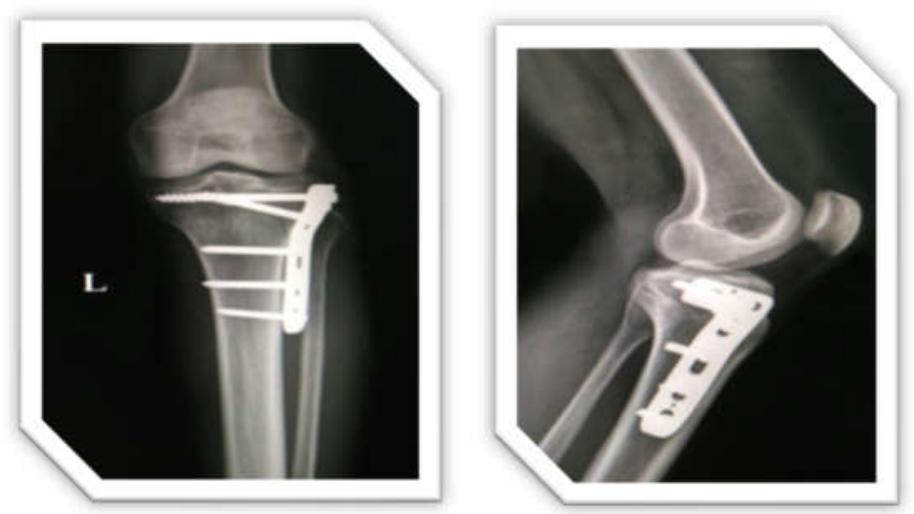

Figure-5:12 weeks post operative follow-up - X-ray of patient 


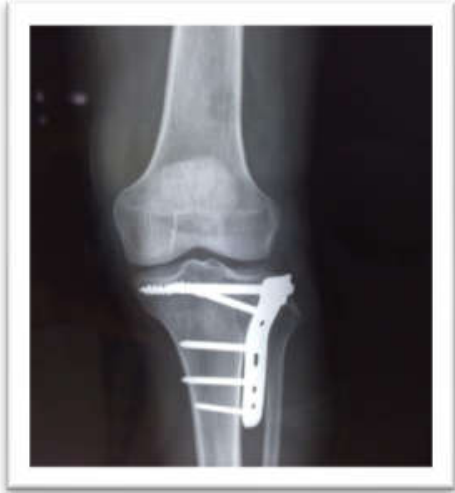

\section{Research Article}

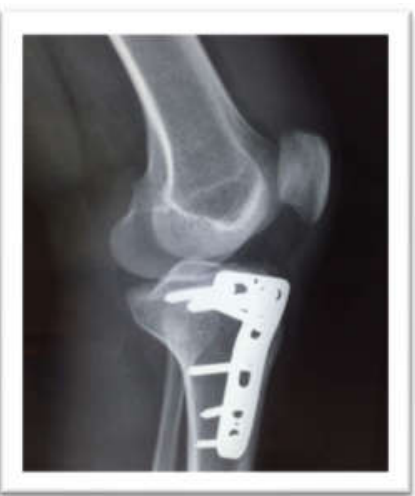

Figure-6:24 weeks post operative follow-up - X-ray of patient

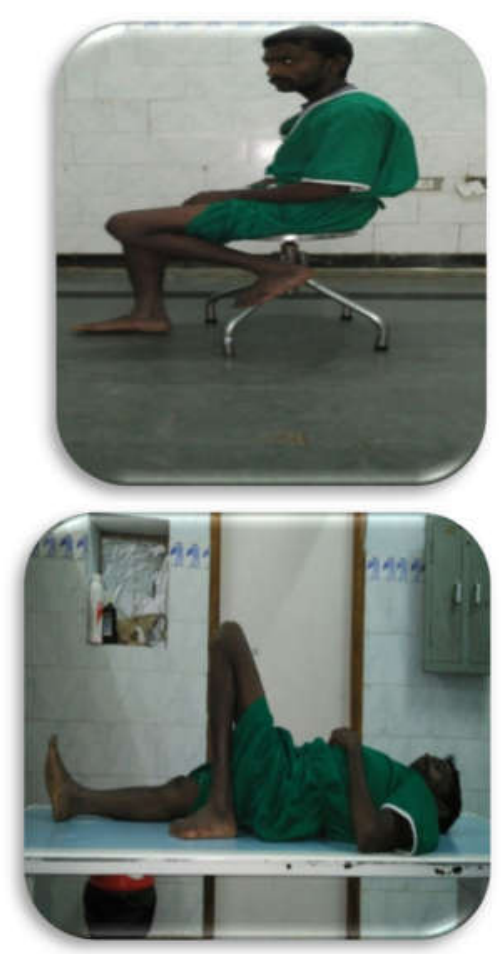

Flexion
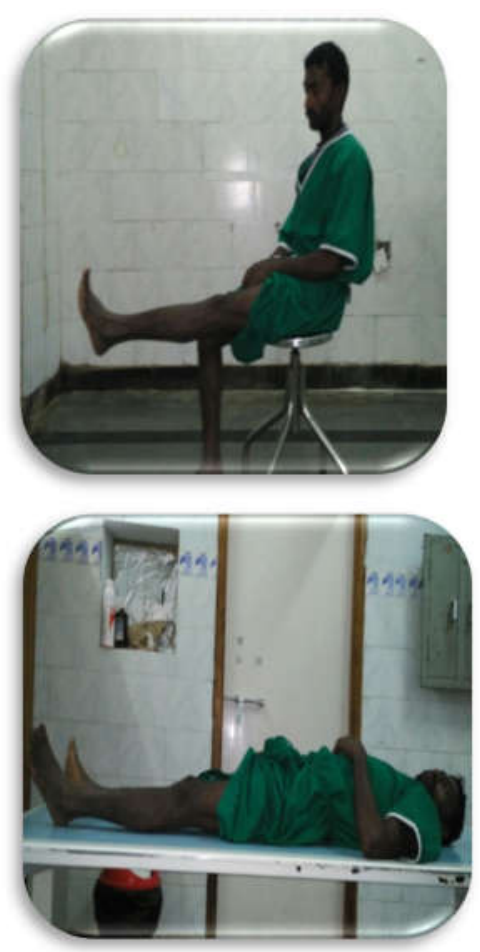

Extension

Figure-7:After 24 weeks of post operative follow-up-clinical outcome

\section{Results}

Table-1: Basic characteristics

\begin{tabular}{|c|c|c|}
\hline Characteristics & No. of cases & Percentage \\
\hline Sex & & 80 \\
\hline Male & 16 & 20 \\
\hline Female & 4 & 15 \\
\hline Age (years) & 3 & 25 \\
\hline $21-30$ & 5 & 25 \\
\hline $31-40$ & 5 & 30 \\
\hline $41-50$ & 6 & 5 \\
\hline $51-60$ & 1 & \\
\hline Above 60 & & \\
\hline
\end{tabular}


Majority of patents belongs to male $16(80 \%)$ followed by female 4(20\%). The median age was 44 years ranging from $22-$ 68 years. Majority patients belongs to age group 31-60 years (Table-1).

Table-2: Distribution of injury related parameters.

\begin{tabular}{|l|c|c|}
\hline & No. of cases & Percentage \\
\hline Type of fracture - Schatzker & 1 & 5 \\
\hline Type I & 2 & 10 \\
\hline Type II & 6 & 30 \\
\hline Type III & 5 & 25 \\
\hline Type IV & 5 & 25 \\
\hline Type V & 1 & 5 \\
\hline Type VI & & \\
\hline Mechanism of injury & 18 & 90 \\
\hline Road traffic accident & 2 & 10 \\
\hline Fall from height & & \\
\hline Side affected & 9 & 45 \\
\hline Right & 11 & 55 \\
\hline Left & 9 & \\
\hline
\end{tabular}

Majority of patients had type-III fracture (30\%) followed by type IV (25\%) and type V (25\%). Road traffic accident $(90 \%)$ was major mechanism for injury. Almost equally on both side, injury was affected (Table-2).

Table-3: Relationship between mechanism of injury with age and sex

\begin{tabular}{|c|c|c|}
\hline Characteristics & Vehicular accident (\%) & Fall from height (\%) \\
\hline Age (years) & & 0 \\
\hline$<50$ & $14(70)$ & $2(10)$ \\
\hline$>50$ & $4(20)$ & $1(5)$ \\
\hline Sex & & $1(5)$ \\
\hline Male & $15(75)$ & \\
\hline Female & $3(15)$ & \\
\hline
\end{tabular}

Age was statistically significant associated with mechanism of injury $(\mathrm{P}=0.01)$, whereas sex is not statistically significant associated with mechanism of injury $(\mathrm{P}>0.05)($ Table-3).

Table-4: Surgery related parameters

\begin{tabular}{|l|c|c|}
\hline & Vehicular accident (\%) & Fall from height (\%) \\
\hline Injury-Surgery Interval (days) & 5 & 25 \\
\hline 1 to 3 & 15 & 75 \\
\hline 4 to 7 & 0 & 0 \\
\hline More than 7 & 5 & 25 \\
\hline Operative time (minutes) & 12 & 60 \\
\hline$<90$ min & 3 & 15 \\
\hline $91-120$ min & & 65 \\
\hline$>120$ min & 13 & 35 \\
\hline Type of Reduction & 7 & \\
\hline CLOSED & & 40 \\
\hline OPEN & 8 & 45 \\
\hline Union (Weeks) & 9 & 10 \\
\hline$<16$ & 2 & 0 \\
\hline $16-18$ & 0 & 0 \\
\hline $19-20$ & 0 & 5 \\
\hline $21-22$ & 1 & \\
\hline Delayed union & & \\
\hline Non union & & \\
\hline
\end{tabular}


Research Article

Internal fixation was considered after patient's general and medical condition was stabilized. Average injury-surgery interval was 4-6 days.

All patients were operated within 7 days 5 of them within 3 days of injury. Average time duration of surgery was 103 minutes with shortest duration being $75 \mathrm{~min}$ and longest being $150 \mathrm{~min}$.

Of 20 patients, 19 Patients (85\%) showed radiological UNION within 18 weeks. One patient went for NONUNION with implant failure. Broken plate was removed and treated with Limb Reconstruction system and bone grafting which united over 16 weeks following second procedure(Table-4).

\section{Discussion}

In the present study 20 were with fracture upper end of tibia. Overall final outcome of the surgical management ofupper end of tibia using locking compression plate was assessed in terms of regaining the lost knee function usingRasmussen criteria [8].

Tibial plateau fractures are more commonly seen in the active productive age group (22-50 years) due to highenergy trauma. Correlated well with the study, Seppo also showed age incidence 20-60 years with an average of 39.8 years which correlates with the present study [9].

Occupationally proximal tibial fractures were seen in people with high level of activity, movement and travel. It is most commonly seen with people who travel more.

In the present study the commonest mode of injury being the road traffic accident $90 \%$ other being fall from height $10 \%$. In our series majority of the patients were Males. This can be attributed to more involvement in RTA.16 patients were males and 4 patients were females. The significance of tibial plateau fracturerelated sex distribution was not available to comment on them. This can be attributed to our Indian setup where the female population largely work indoor and do not travel much. In the present study, there was Left sided predominance, compared to the right side with left side 11 patients (55\%) and right side 5 patients( $45 \%)$.

All 20 cases studied in our series were closed. The median age was 44 years ranging from 22-68 years. 18 of the fractures were caused by road traffic accidents and 2 were due to fall. In this series, 20 cases were studied, out of them most of the patients fall into type III,type IV, type V and type VI schatzker's classification.

Different authors use different criteria for the surgical management of these fractures. SEPPO E. Honkonen [9] conducted 130 tibial plateau fractures taking into consideration of Condylar widening of $>5 \mathrm{~mm}$
- Lateral condyle step off $>3 \mathrm{~mm}$

- All medial condylar fracture

In the present series the indications for the surgery were the same standard indications as for the tibial plateau fractures. $3 \mathrm{~mm}$ depression was considered as indications for surgery in the present series.

In the present series MIPO techniquewas used for reduction and fixation in 13 patients $65 \%$. In which both duration of procedure and soft tissue injuries are less compare to ORIF technique, wound healing also better and faster compare to ORIF technique but it demands more surgical techniques.

In the present series antero medial incision was approached in 7 patients this approach need less soft tissue stripping from bone can contour plate to bone appropriately and easy to perform MIPPO technique and it was preferred that antero lateral approach in 13 patients with lateral condylar displacement fracture and soft tissue injury on medial side of proximal tibia. In a study on fracture upper end of tibia by Peter A. Cole the mean age of the patients was 45 years (range: $16-82$ years).

There were 22 female patients and 53 male patients. The mechanism of injury was a motor vehicle collision in 48 patients, a fall or twisting injury in 16 patients, gunshot injury in 6 patients, and other high-energy mechanisms in 5 patients [3].

In the present study, of the 20 'upper end of Tibia' fractures, 16 were due to road traffic accident and 2 were due to fall from height. 2 were of SchatzkertypeI; 2 were of Schatzker type II; 6 were of Schatzker type III, 5 were of Schatzker type IV, 5 were of Schatzkertype V, and remaining 1 was of Schatzker type VI.

In a study by Peter A. Cole [3] Internal fixation using the LCP was performed at an average of 7.1 days (range: 0-29 days) after the injury. Twenty-two 


\section{Research Article}

fractures were operated on within the first 24 hours. The implants used for the fractures in this series included 6 5-hole, 43 9-hole, and 28 13-hole fixators. The mean number of locking screws used in the proximal articular segment was 4.9 (range: 3-7 screws), and the mean number of screws used in the distal segment was 4.8 (range: 2-6 screws).

In 53 patients, adjunctive implants were used for periarticular fixation, which included 6 plates (smallfragment plates), $1 \mathrm{~K}$-wire, and articular lag screws in 49 fractures. Allograft bone grafting was performed in 9 cases of tibial plateau fractures, where voids from depressed plateau fracture fragments had to be filled and buttressed.

In the present study for fixation of fracture upper end of tibia, the average injury surgery interval was 7 days. 7 to 9 holed plates were used in $60 \%$ of patients. The mean number of locking screws used in the proximal articular segment was 4 and the mean number of screws used in the distal segment was also 4, similarly to the study by Peter A cole and colleagues[3].

19 out of 20 upper tibial fractures showed clinical and radiological union in average period of 16 weeks following surgery. 1 patient went for non union due to implant breakage.

In 1 patient, plate breakage was encountered. Breakage in this case is mainly attributed to the patient factor as patient did not come for follow up in the initial 3 months postoperatively and started walking before the clinical and radiological union of fracture. Second surgical procedure was done. Broken plate was removed and treated with limb reconstruction system and bone grafting. Fracture healed well 14 weeks after the second procedure.

The LISS is akin to an internal fixator, which provides comparable stability to double-plating constructs in a biomechanical evaluation by Goeslinget al [10]. Peter A Coleet al have shown that the LISS fixator for treatment of proximal tibia fractures, which has similar material and design characteristics as the tibial LISS fixator, provides superior fixation in osteoporotic bone compared with the blade plate and retrograde IM nail [3]. This series has demonstrated that its use prevents varus collapse in bicondylartibial plateau fractures.

M. Ahmad et alstudied on biomechanics of locking compression plate.Consistentresults were achieved in LCP constructs in which the plate was applied at or less than $2 \mathrm{~mm}$ from the bone. When applied $5 \mathrm{~mm}$ from the bone the LCP demonstrated significantly increased plastic deformation during cyclical compression and required lower loads to induce construct failure [11].

Kenneth A. Egolet alconducted a study on Biomechanics of Locked Plates andScrews and showed that Locked plates and conventional plates rely on completely differentmechanical principles to provide fracture fixation and they provide different biologicalenvironments for healing doing so. Locked plates may increasingly be indicated for indirect fracture reduction, diaphyseal/metaphyseal fractures in osteoporotic bone, bridging severely comminuted fractures, and the plating of fractures where anatomical constraints prevent plating on the tension side of the bone [12].

Another word of caution is merited regarding the timing of definitive operative intervention, particularly for the high-energy, bicondylar, tibial plateau fracture. Although it is true that smaller incisions may be used, this does not obviate the need for patience to allow the soft tissue swelling to subside after injury. In study by Peter A Coleet al [3], the average time for LISS implantation was 7 days after the injury, and it was performed up to 29 days after the injury.In our series, surgery was performed at an average of 5 days following injury.

Oh JKet al [13] performed Percutaneous plate stabilization of proximal tibial fractures in about 24 proximal tibia fractures. All fractures healed. The average time for fracture healing was 16.5 weeks (range, 8-24 weeks). Complications included one case of shortening $(1 \mathrm{~cm})$ and two cases of misalignments; one valgus of 6 degrees and one varus of 5 degrees. There was one case of superficial infection that was healed after removal, but no patient showed deep infection. Results were evaluated by the modified Rasmussen scoring system. Most patients had excellent or good results; only one patient had fair results.

Results were evaluated by the modified Rasmussen scoring system. Most patients had excellent or good results; only one patient had fair results.Phisitkul Pet al [14] conducted a study on Complications of locking plate fixation in complex proximal tibia injuries in about 37 patients.Twelve fractures (32\%) healed without any complications. Eight patients (22\%) developed deep infections that required operative debridement, and 5 of them had a hardware removal; 1 eventually required an above-knee amputation. Eight 


\section{Research Article}

cases $(22 \%)$ had postoperative misalignment, with hyperextension as the most common deformity. Three cases $(8 \%)$ had loss of alignment into varus during healing. Other complications were 1 superficial wound dehiscence, 1 delayed soft-tissue breakdown, 4 hardware irritations, 1 peroneal nerve injury at the distal part of a 9-hole plate, 1 tibial tubercle nonunion, and 1 postoperative compartment syndrome.

In the present study 19 cases had no complications and one case had implant breakage attributed to patients poor follow up. Jain Ret al [15]conducted Prospective Case Study of Outcome of Tibial Plateau Fractures Treated with Locking Compression Plate. The study was conducted on thirty patients admitted in the department of orthopaedics with diagnoses of tibial plateau fractures treated with Locking Compression Plate. The patients were followed up for a minimum period of six months and clinico-radiological progression of fracture union with the functional outcome was studied using 100 point rating system devised by Delamarter et al [16].

Twenty-two patients showed excellent results while eight patients had good to fair and none with poor result. The average time for radiological union was 17.5. In our 19 out of 20 upper tibial fractures showed clinical and radiological union in average period of 16 weeks following surgery. One case had implant breakage. In our series one patient developed knee stiffness due to patella fracture treated with patellectomy and physiotherapy and regain $70^{\circ}$ of flexion another patient present with knee joint instability at end of 6 months of postoperative period he was treated with ACL reconstruction and physiotherapy and he regained a range of movement from complete extension to $90^{\circ}$ of flexion.

In the presentstudy, one patient had associated anterior crutiate ligament injury he was treated with above knee pop cast till fracture union and advised to wear knee support while walking and to undergo ACL repair in subsequent days.

The period of immobilization was again individualized depending on the Stability of fixation. The benefits of early knee mobilization include reduced incidence of knee stiffness and improved cartilage healing (regeneration) and promotion of good callus formation and remodelling.

Results were evaluated by the modified Rasmussen scoring system. In the present study on 20 fractures of proximal tibia, 14 patients showed excellent result. 5
Patients showed good outcome and 1 patient showed poor outcome.

Study limitations:Further study in large number of patients is required to comment regarding disadvantages and complications.

\section{Conclusion}

Locking compression plate is the optimal tool for proximal tibia fractures. It provides rigid fixation in the upper end of tibia, where a wide canal, thin cortices and frequently poor bone stock make fixation difficult.

Locking Compression Plate is an important armamentarium in treatment of fractures around knee especially when fracture is severely comminuted and in situations of osteoporosis. Further study in large number of patients is required to comment regarding disadvantages and complications.

\section{What the study adds to the existing knowledge?}

Literature on efficiency of locking compression plate for fracture has shown different outcome rates which make a meaningful adding in existing literature by conducting the present study in the study area for timely recognition and understanding of common issues related to LCP for fracture.

Author's contribution by authors during study
process and manuscript preparation: Dr. D.Rama Rao: Study design and manuscript preparation.

Dr.K. Ravi Kanth: Study design and manuscript preparation

Conflict of interest: None declared.

Funding: Nil, Permission from IRB: Yes

\section{Reference}

1. Kenneth. A. Egol and Kenneth J Koval , In: Fractures of proximal tibia: chapter 50, Rockwood and Green's "Fractures in Adults", Vol. 2, 6 ${ }^{\text {th }}$ edition, Lippincott Williams and Wilkins, 2010.

2. Charles .M. Court-Brown, In: Fractures of tibia and fibula chapter 52, Rockwood and Green's "Fractures in Adults", Vol. 2, $6^{\text {th }}$ edition, Lippincott Williams and Wilkins, 2010.

3. Cole PA, Zlowodzke M, Kregor PJ. Treatment of proximal tibial fractures using the Less Invasive 


\section{Research Article}

Stabilisation System: Surgical Experience And Early Clinical results in 77 fractures. J OrthopaedTrauma. 2004; 18(8):528-535.

4. Egol KA, Su E, Tejwani NC, Sims SH, Kummer FJ, Koval KJ. Treatment of complex tibial plateau fractures using the less invasive stabilization system plate: clinical experience and a laboratory comparison with double plating. J Trauma Injury Infect Critical Care. 2004;52(2): 340-346.doi: 10.1097/01.TA.0000112326. 09272.13

5. Sommer C, Wullschleger M, Walliser M, Bereiter H, Leutenegger A. Experience with the locking compression plate (LCP) in fracture treatment of osteoporotic bone. British J Surg. 2004;91(7):912.

6. Girisha BA, Rajesh P, Kumar SC, Muralidhar N. Surgical management of proximal tibial fractures with locking compression plate. Int J Res Orthop 2017;3(4): 756-60.doi: http://dx.doi.org/10.18203/issn.2455-4510. Int JRes Orthop20172549

7. Stannard JP, Wilson TC, Volgas DA, Alonso JE. Fracture stabilization of proximal tibial fractures with the proximal tibial LISS: early experience in Birmingham, Alabama (USA). Injury. 2003;34(1):A3642.doi: https://doi.org/10.1016/S0020-1383(03)00256-0

8. Rasmussen PS. Tibial condylar fractures: impairment of knee joint function as an indication for surgical treatment. J Bone Joint Surg Am. 1973;55(7):1331-50.

9. Honkonen SE. Indications for surgical treatment of tibial condyle fractures, Clin Orthopaed. 1994;302;199205.
10. Gosling T, Schandelmaier P, Muller M, Hankemeier S, Wagner M, Krettek C. Single lateral locked screw plating of bicondylar tibial plateau fractures. Clinic Orthopaed Related Res. 2005; 439:207-14.

11. Ahmad M, Nanda R, Bajwa AS, Candal-Couto J, Green S, Hui AC. Biomechanical testing of the locking compression plate: when does the distance between bone and implant significantly reduce construct stability?Injury.2007;38(3):358-364.doi: https:// doi.org / 10. 1016/j.injury.2006.08.058

12. Kenneth A. Egol and Kenneth J Koval, In: Fractures of proximal tibia: chapter 50, Rockwood and Green's "Fractures in Adults", Vol. 2, 6th edition, Lippincott Williams and Wilkins 2006.

13. Oh CW, Oh JK, Min WK, Jeon IH, Kyung HS, Ahn $\mathrm{HS}$, et al. Management of ipsilateral femoral and tibial fractures. Int Orthopaed. 2005;29(4):245-50.doi: 10. 1007/ s00264-005-0661-7

14. Phisitkul P, McKinley TO,Nepola JV, Marsh JL. Complications of Locking plate fixation in complex proximal tibia injuries. J Orthop Trauma. 2007;21 (2): 83-91.doi: 10.1097/BOT.0b013e318030df96

15. Jain R Prospective case dtudy of outcome of tibial plateau fractures treated with Locking Compression plate.Malays Orthop J. 2016;10(3):12-16.doi: 10.5704/ MOJ.1611.007

16. Delamarter RB, Hohl M, Hopp JE. Ligament injuries associated with tibial plateau fractures. ClinicOrthopaed Related Res. 1990(250):226-33.

\section{How to cite this article?}

Rao D.R, Kanth K.R. Study on efficiency of locking compression plate for fracture of upper end of tibia. Surgical Update: Int J surg Orthopedics. 2019;5(3):189-198. doi:10.17511/ijoso.2019.i03.10. 